\title{
BMJ Open Within-individual analysis of pain and sickness absence among employees from low and high occupational classes: a record linkage study
}

\author{
Aapo Hiilamo, ${ }^{1}$ Peter Butterworth, ${ }^{2,3}$ Rahman Shiri, ${ }^{1}$ Annina Ropponen, ${ }^{1}$ \\ Olli Pietiläinen, ${ }^{4}$ Minna Mänty, ${ }^{4,5}$ Anne Kouvonen, ${ }^{6,7,8}$ Eero Lahelma, ${ }^{4}$ \\ Ossi Rahkonen, ${ }^{4}$ Tea Lallukka ${ }^{1,4}$
}

To cite: Hiilamo A, Butterworth P, Shiri R, et al. Within-individual analysis of pain and sickness absence among employees from low and high occupational classes: a record linkage study. BMJ Open 2019;9:e026994. doi:10.1136/ bmjopen-2018-026994

- Prepublication history and additional material for this paper are available online. To view these files, please visit the journal online (http://dx.doi. org/10.1136/bmjopen-2018026994).

Received 1 October 2018 Revised 3 January 2019 Accepted 1 February 2019

Check for updates

(C) Author(s) (or their employer(s)) 2019. Re-use permitted under CC BY-NC. No commercial re-use. See rights and permissions. Published by BMJ.

For numbered affiliations see end of article.

Correspondence to

Aapo Hiilamo;

aapo.hiilamo@ttl.fi

\section{ABSTRACT}

Objectives Pain is linked to an increased risk of sickness absence (SA); however, the extent to which unmeasured time-invariant differences explain this association is yet unknown. Therefore, we determined the within-individual associations between pain and short-term (in the survey year) and long-term (2 years following the survey years) SA risk in high and low occupational classes while controlling for the potential bias due to unobservable time-invariant characteristics.

Methods The Helsinki Health Study data consisting of midlife public sector employees with mailed surveys from up to four time points, and SA record linkage were used (3983 persons). The within-individual estimates were calculated using hybrid negative binomial regression models.

Results Acute/subacute pain was associated with a $13 \%$ increase in the rate of short-term SA days (incidence rate ratio 1.13 [95\% $\mathrm{Cl} 1.01$ to 1.27$]$ ), while the association was somewhat stronger for chronic pain (1.32 [1.191.47]). For the employees in the low occupational class, these associations were robust (1.29 [1.10-1.50] for acute/subacute and 1.43 [1.23-1.66] for chronic pain), whereas only chronic pain was associated with SA among those in the high occupational class (1.25 [1.08-1.46]). Chronic pain was also associated with SA days in the long term without occupational class differences. Similar results were obtained for multisite pain (pain in several locations). Conclusions These results indicate that particularly chronic and multisite pain have a within-individual link to SA but ignoring unobservable differences between those reporting pain and those not might yield overstated effect sizes. Pain might have a different relation to SA in low and high occupational classes.

\section{INTRODUCTION}

The prevalence of pain is substantial among midlife employees, ${ }^{1}$ and there is an increasing body of evidence showing that employees reporting pain have a higher risk of sickness absence (SA), especially due to musculoskeletal disorders, compared with those not reporting any pain. ${ }^{2-8}$ However, it is yet
Strengths and limitations of this study

- Unlike previous studies, we examined the within-individual link between pain and sickness absence while controlling for all time-invariant confounding characteristics.

- Longitudinal data on sickness absence were derived from employer's administrative records containing all absence days.

- Both pain chronicity and the number of pain locations were examined.

- As a limitation, our estimates might be conservative due to health-related drop out from paid employment.

unknown whether variability in an individual's experience of pain over time is associated with differences in their likelihood of SA. In other words, whether the association between pain and SA exists at the within-individual level when all time-invariant characteristics are controlled for.

In the previous studies, the methodological strategy has been the between-individual comparison, that is, the comparison of the subsequent SA risks between the individuals reporting and not reporting pain at a single time-point after adjusting for observable confounding factors. ${ }^{2-4}$ 9-11 A major limitation of such approach is the potential omitted variable bias, ${ }^{12}$ meaning that unmeasured differences between participants in the two groups may explain the relationship between pain and SA.

The within-individual, also known as fixed effect, regression analysis has been advocated as an appropriate statistical approach to control for the omitted variable bias in longitudinal studies. ${ }^{13}$ The method takes advantage of multiple measures per person by using each person as his/her own control 
and focusing on the within-individual changes during the study period. ${ }^{14}$ In essence, the method compares individuals with themselves, instead of focusing on the differences between different individuals and, as a result, controls for all time-invariant characteristics of individuals. The within-individual method is particularly relevant to pain as there might be important unobservable individual characteristics that are linked to both pain reporting and a higher risk of SA, such as weak immune system. ${ }^{15}$ While some studies have employed within-individual approach on research regarding other determinants of $\mathrm{SA}^{16-19}$ we are unaware of any prior studies using this approach to investigate the association between pain and SA.

It is also uncertain whether the pain-SA association differs between employees from high and low occupational classes. Studies where pain has been measured at one time-point suggest that work environment might act as an important moderator of the pain-SA association. ${ }^{92}$ However, the role of the occupational class as such moderator needs to be confirmed.

The present study investigates the short (the number of SA days in the survey year) and long-term (the 2-year number of SA days following the survey year) within-individual association between pain and SA days among employees in low and high occupational classes. As advocated in the previous studies on the pain-SA association, we focus on both acute/subacute and chronic pain, and separately the number of pain locations. ${ }^{62122}$ It is hypothesised that within-individual change in pain will be associated with within-individual change in SA, and that this association may be stronger among those in a low occupation class for whom maintaining engagement in work with pain may be more difficult. It is further hypothesised that the associations will be stronger for short-term than the longer-term SA, in part because pain will be more likely to lead to disability retirement. ${ }^{23}$

\section{METHODS}

\section{Data}

This study uses a sample from the Helsinki Health Study (HHS) consisting of midlife employees (at baseline 40-60 years old) of the City of Helsinki, Finland. HHS is a well-established ongoing cohort study with satisfactory to high response rates in mailed surveys at all study phases $(67 \%-83 \%)$. The cohort data are extensively linked to the employer's as well as national administrative registers about SA. More details of the HHS cohort can be found elsewhere. ${ }^{24}$ We included employees who consented to the linkage of their survey responses to the employer's SA records, and were respondents at baseline (20002002) and at least one follow-up survey (2007, 2012 or 2017) while still employed the whole survey calendar year (see online supplementary figure S1). Observations with missing items on the covariates were dropped from the analyses (553 employees excluded). The main analytical sample consisted of 3983 employees with the total of 11009 observations.
To investigate whether the association between pain and SA is moderated by occupational class, we split the sample into two groups: employees in high and low occupational classes. Following previous procedures ${ }^{25}$ employees in administrative/managerial, professional and semiprofessional occupations were categorised as 'high occupational class' (54\% at the baseline) and employees in routine non-manual, and manual occupations were grouped into 'low occupational class' (46\%). Occupational class was derived from the employer's personnel register and, for the very few with no such register-based information, completed from questionnaires. Our occupational measure was time varying and measured at each follow-up, meaning that a person could change from one occupational group to another during the follow-up period. However, we show some of the descriptive statistics by the baseline occupational group.

\section{Patient and public involvement}

Patients and or public were not involved in the design phase of the study.

\section{Measures}

Outcome: SA

Information on SA was obtained from the employer's register containing all SA days for any cause. We used two different measures of SA. The first measure, used in studying the short-term association between current pain and SA, was the annual number of SA days in the same calendar year as the surveys were conducted. For this measure, up to three within-individual changes were possible (2000/2002-2007, 2007-2012 and 2012-2017). The second measure, reflecting long-term associations between pain and $S A$, was the 2-year cumulative number of SA days in the calendar years following the survey year (ie, the survey year was not included). For this measure, the employees were required to be employed by the City of Helsinki at least 2 full calendar years after the survey year. For the second measure, up to two within-individual changes were possible, and the study population was smaller as the employees were required to work until the year 2009 and the fourth phase survey (2017) was not yet available for the analyses (see online supplementary figure S2).

\section{Main exposure: pain}

Pain was asked similarly in the baseline and follow-up surveys. We collected data on both acute/subacute and chronic pain as their associations with work disability and health-related functioning differ. ${ }^{522}$ The employees were first asked whether they were currently experiencing any pain ('Are you having any pain or ache at the moment?') and then separately the duration of the pain ('When did the pain or ache start?' 3 months or less/over 3 months ago). Following the conventional classifications,${ }^{26}$ pain lasting up to 3 months was defined as acute/subacute pain and pain lasting more than 3 months was defined as chronic pain. Previous investigations using the same data 
showed that this pain measure is a robust predictor of work disability, particularly due to musculoskeletal disorders, ${ }^{27}$ and physical functioning. ${ }^{22}$

We additionally conducted analyses with multisite pain, as an alternative measure of pain, which has shown to have a stronger link to work disability than pain in a single site only. ${ }^{62829}$ Employees were asked whether they were currently experiencing acute/subacute or chronic pain in seven body locations (head/face, neck/shoulders, low back, lower limbs, upper limbs, stomach and a self-reported location). We classified the number of pain locations into none, one, two and three or more. For this measure, those reporting pain but not reporting the pain locations were set as missing observations causing a slightly smaller analytical sample (10 849 observations).

\section{Covariates: health}

Only time-varying covariates were included as the within-individual analysis implicitly controls for all time-invariant characteristics including sex. Health was assessed with two dichotomous measures, namely self-reported long-standing illness (yes/no) and common mental disorders (CMDs). CMDs were measured by a 12 -item version of the General Health Questionnaire (GHQ-12) ${ }^{30}$ with binary indicator variable based on a standard cut-point of 3 or more, which have been proved as a robust predictor of various mental health outcomes in the present cohort data, including disability retirement due to mental causes. $^{31}$

\section{Work characteristics}

Given their association with both pain and SA, several previously used, self-reported, dichotomised and time-varying measures of working environment were included. ${ }^{32} 33$ The employees were asked how physically and mentally strenuous they regarded their working environment with four response options: very light, somewhat light, somewhat strenuous and very strenuous. Due to different distributions, in mental working environment very strenuous option was coded as having a strenuous mental working environment; and in physical working environment somewhat and very strenuous options were coded as having a strenuous physical working environment. Furthermore, we included a time-varying low job control variable. Employees who fully or somewhat agreed with the statement 'On my job, I have very little freedom to decide how to do my work' were classified as having low job control. A dichotomous time-varying variable of reported part time work was included as part-time workers have a lower risk of SA and their exposure to work-related factors is shorter. In addition, given its established association with both pain and SA, we also included a time-varying dichotomous variable representing night or shift work (vs others). ${ }^{34}$

\section{Other covariates}

All models included a categorical survey phase variable to account for the differences due to the measurement phase and potential changes in the workplace and SA compensation. Finally, a dichotomous and potentially time-varying variable of marital status was also included (cohabiting/married vs never married/divorced/ widowed)..$^{35}$

\section{Statistical methods}

The short-term and long-term associations between pain and SA were examined with a within-individual estimation approach. This method controls for all time-invariant factors, both observable and unobservable, by assessing the association between changes in independent variables and corresponding changes in an outcome variable at the within-individual level. ${ }^{14}$ The coefficient should, therefore, be interpreted as the within-individual association between a change in the independent variable and the corresponding change in the outcome variable.

Negative binomial distribution was chosen over Poisson due to overdispersion in the outcome variables. Given the methodological problems with fixed-effect negative binomial regression models in mainstream statistical software packages such as Stata, ${ }^{36}$ we followed advocacy by Allison ${ }^{37}$ and previous examples from the SA research, ${ }^{18} 19$ and obtained the within-individual estimates from a hybrid model, also known as the 'within-between' estimator, for example. ${ }^{38}$ Random-effect models were fitted with both person-specific mean scores of each time-varying variable and person-specific deviation scores as regressors. In this hybrid model, the person-specific mean scores estimate the between-individual associations, whereas the person-specific deviation scores (ie, deviations from the person-specific means of each time-varying variables) illustrate the within-individual associations. ${ }^{39}$ Only the within-individual estimates are presented in the tables, while the between-within-individual estimate comparisons are shown in figure 1. For the between-within-individual estimate comparison, we additionally included also a number of time-invariant variables (sex, age at baseline and Body Mass Index).

The models were fitted for all employees and separately for the employees classified in the low and high occupational classes. It is noteworthy that a same employee was potential present in both models if he/she changed from one occupational class to another during the observational period. In the first models studying the shortterm association, the annual SA days in the survey year was the outcome variable. The second models focused on the longer-term association. The 2-year cumulative number of annual SA days in the calendar years following the survey year was the outcome in these analyses. The potential occupational class differences in the effect of pain were tested with a separate occupational class interaction model. Given the many possible interpretations of interaction effects when both interacted variables are time-varying in within-individual regression models, we created time-invariant occupational class variable, which represented a person's mean occupational class value over his/her observational period. Interaction terms with 

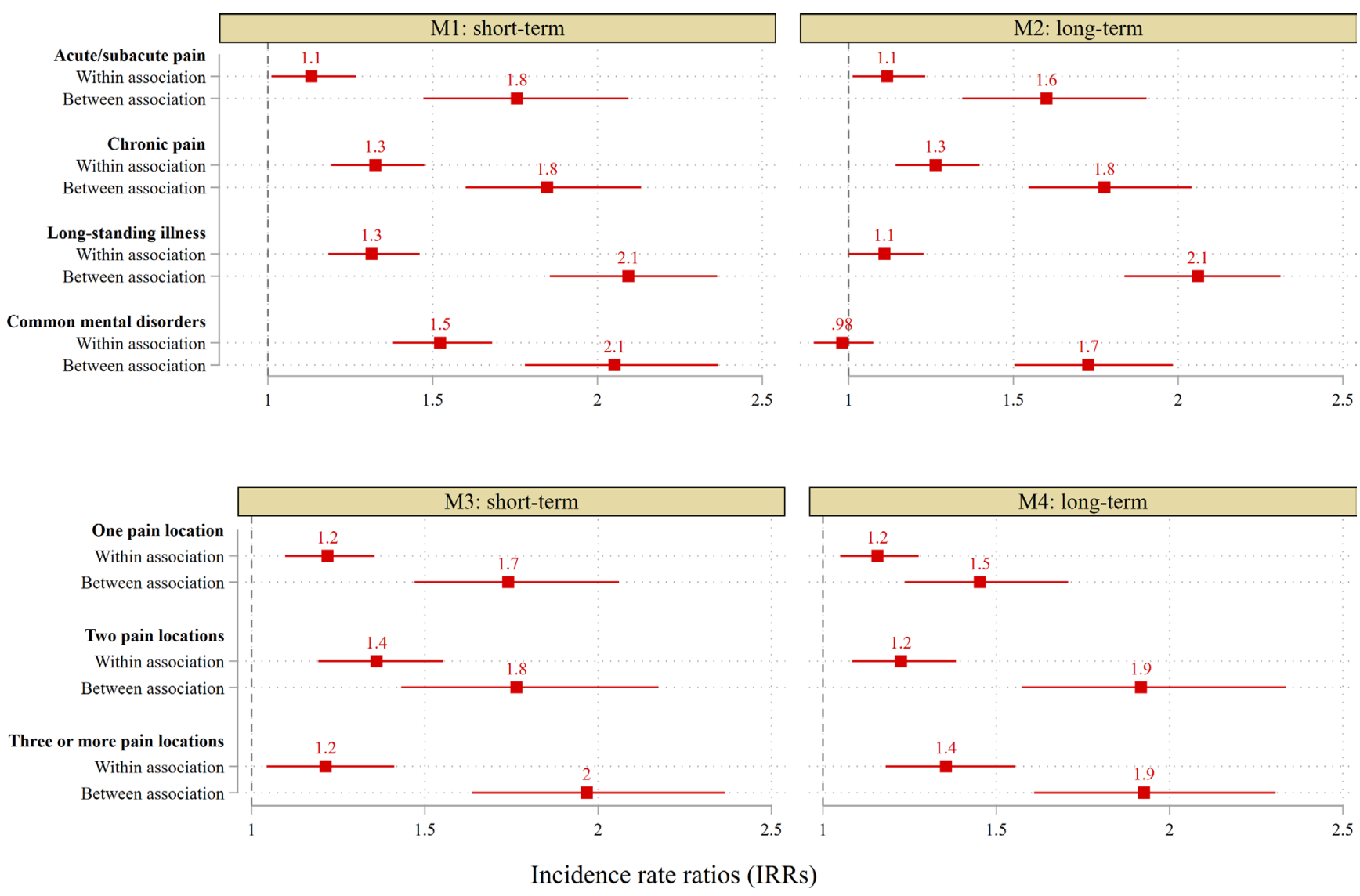

Figure 1 Decomposition of the between-within associations with sickness absence (SA). Incident rate ratios (IRRs) are from a hybrid negative binomial regression. All models adjusted for time-varying long-standing illness, common mental disorders, marital status, part-time work, strenuous physical work, strenuous mental work, job control, occupational status and night/ shift work. Additionally, time-unvarying age at baseline, sex and body mass index (normal weight, overweight and obesity). All differences shown in the between-individual versus within-individual estimates are statistically significant $(p<0.05)$. Shortterm, within the survey year; long-term=during 2 years after the survey year.

time-invariant occupational class and the pain variables, and other variables which differed between the occupational classes in the stratified models were included in this model (only p-values showed).

As no significant sex interactions were found in the main model, we did not stratify the analysis by sex. Due to the medium proportion of item missing responses, we also replicated our analyses using multivariate imputation by chained equations, but these did not change substantively our results, so we report the results from the complete case analyses. However, the results using imputations are shown in the supplementary materials (online supplementary tables S1-S3). The coefficients were transformed to enable interpretation as incidence rate ratios (IRR). Stata 15 and user-written xthybrid command by Schunck and Perales for the within-individual estimates were used. $^{39}$

\section{RESULTS}

\section{Characteristics}

As shown in table 1, the study population consisted of more female than male employees $(82 \%)$ with a mean age of 47.2 years at baseline. Both baseline occupational classes had a similar mean number of observations per person (2.8 and 2.7). The employees when in the high occupational class had the mean number of 9.1 SA days in the short term (the survey years), while the mean was 16.5 days for the low occupational class. The difference in SA was similar when SA was measured in the long term (the subsequent 2 year mean of 18.8 vs 33 days). The employees when in the low occupational class were more likely to report acute/subacute and chronic pain as well as longstanding illness than those in the high class thorough the follow-ups. Furthermore, the employees in the high occupational class reported more mentally strenuous work and less physically strenuous work than employees in the low occupational class.

Within-individual changes in pain were common (table 2). Around $41 \%$ of the employees with two consecutive observations changed their pain status; $19 \%$ reported decrease in pain and $22 \%$ increase in pain (ie, increase from no pain to acute/subacute pain or from acute/subacute pain to chronic pain). Some $66 \%$ of the participants reported pain at some point of the study and, therefore, only $34 \%$ of the participants did not have any pain at any time point of the study. Around half of the 
Table 1 Descriptive statistics of the study population, the Helsinki Health Study

\begin{tabular}{|c|c|c|c|}
\hline & \multicolumn{3}{|c|}{ Occupational class at baseline } \\
\hline & High & Low & Total \\
\hline & $\begin{array}{l}\mathrm{N} / \mathrm{Col} \% / \\
\text { mean }\end{array}$ & $\begin{array}{l}\mathrm{N} / \mathrm{Col} \% / \\
\text { mean }\end{array}$ & $\begin{array}{l}\mathrm{N} / \mathrm{Col} \% / \\
\text { mean }\end{array}$ \\
\hline Women $(\%)^{*}$ & 76 & 89 & 82 \\
\hline Mean age at baseline ${ }^{\star}$ & 47.2 & 47.1 & 47.2 \\
\hline Number of persons $(\mathrm{N})$ & 2138 & 1845 & 3983 \\
\hline $\begin{array}{l}\text { Number of observations } \\
\text { (n) }\end{array}$ & 6025 & 4984 & 11009 \\
\hline \multirow{2}{*}{$\begin{array}{l}\text { Mean number of } \\
\text { observations per person } \\
(2-4)\end{array}$} & 2.8 & 2.7 & 2.8 \\
\hline & \multicolumn{3}{|c|}{ Occupational class (potentially time-varying) } \\
\hline $\begin{array}{l}\text { Mean number of SA } \\
\text { days } \ddagger\end{array}$ & High & Low & Total \\
\hline $\begin{array}{l}\text { Short-term (the survey } \\
\text { year) }\end{array}$ & 9.1 & 16.5 & 12.3 \\
\hline $\begin{array}{l}\text { Long-term (the } \\
\text { subsequent } 2 \text { year) }\end{array}$ & 18.8 & 33.0 & 25.1 \\
\hline \multicolumn{4}{|l|}{ Pain (\%)‡ } \\
\hline No pain & 61 & 51 & 57 \\
\hline Acute or subacute pain & 14 & 17 & 16 \\
\hline Chronic pain & 24 & 32 & 28 \\
\hline Total & 100 & 100 & 100 \\
\hline \multicolumn{4}{|c|}{ Number of pain locations, 1-7 (\%)‡ } \\
\hline One pain location & 20 & 21 & 20 \\
\hline Two pain locations & 10 & 13 & 11 \\
\hline $\begin{array}{l}\text { Three or more pain } \\
\text { locations }\end{array}$ & 8 & 14 & 11 \\
\hline \multicolumn{4}{|l|}{ Long-standing illness (\%)‡ } \\
\hline No & 59 & 56 & 58 \\
\hline Yes & 41 & 44 & 42 \\
\hline Total & 100 & 100 & 100 \\
\hline \multicolumn{4}{|c|}{ Common mental disorders (\%)‡ } \\
\hline No & 76 & 77 & 76 \\
\hline Yes & 24 & 23 & 24 \\
\hline Total & 100 & 100 & 100 \\
\hline \multicolumn{4}{|c|}{ Mentally strenuous work (\%)‡ } \\
\hline No & 85 & 91 & 87 \\
\hline Yes & 15 & 9 & 13 \\
\hline Total & 100 & 100 & 100 \\
\hline \multicolumn{4}{|c|}{ Physically strenuous work (\%)‡ } \\
\hline No & 84 & 49 & 69 \\
\hline Yes & 16 & 51 & 31 \\
\hline Total & 100 & 100 & 100 \\
\hline \multicolumn{4}{|l|}{ Low job control (\%)‡ } \\
\hline No & 92 & 84 & 89 \\
\hline Yes & 8 & 16 & 11 \\
\hline Total & 100 & 100 & 100 \\
\hline
\end{tabular}

*Proportion of participants.

†Potentially time-varying occupational class (a same person could be potential in both columns).

$\ddagger$ Proportion of observations. participants had at least one observation in which they reported chronic pain and the percentage was higher among those in the low occupational class at the baseline than in the high class ( $54 \%$ vs $44 \%$ ).

Similar characteristics of the SA measures are presented in the online supplementary table S4. Overall, $51 \%$ of the employees had at least one observation in which they did not have any SA days the short term. The figure was higher among those in the high occupation class $(58 \%)$ than in the low class $(42 \%)$ at the baseline. The difference between the two baseline occupational classes was similar for the risk of SA in the long-term.

\section{Acute/subacute and chronic pain}

Table 3 presents the within-individual estimates for the short-term associations between acute/subacute and chronic pain and SA. In the analysis combining all employees, acute/subacute pain was associated with a $13 \%$ increase in the rate of SA days (IRR 1.13 [95 $\%$ CI 1.01 to 1.27$]$ ), while the association was somewhat stronger between chronic pain and SA days (1.32 [1.19-1.47]). The stratified analyses showed that in the low occupational class, chronic pain was associated with a $43 \%$ increase in the rate of SA (1.43 [1.23-1.66]), while the association was somewhat weaker in the high occupational class (1.25 [1.08-1.46]). Furthermore, acute/subacute pain showed an association with SA in the low (1.29 [1.10-1.50]) but not in the high occupational class. For all employees, long-standing illness (1.32 [1.19-1.46]), CMDs (1.53 [1.38-1.69]) and physically strenuous work (1.33 [1.18-1.50]) had short-term within-individual association with SA.

The within-individual estimates for the long-term associations between acute/subacute and chronic pain and SA are presented in table 4 . In the analysis combining all employees, chronic pain was associated with a $26 \%$ increase in the rate of SA (1.26 [1.14-1.39]), but there were no statistically significant differences between the occupational classes. Only in the low occupational class, acute/subacute pain had a weak longterm association with SA (1.17 [1.01-1.34]). In the all employees model, mentally and physically strenuous work were both linked to a $14 \%$ and $17 \%$, respectively, increase in the rate $\mathrm{SA}$ days in the long-term (IRR=1.14 [1.01-1.30] for mentally and IRR=1.17 [1.04-1.30] for physically strenuous work).

\section{Multisite pain}

Analyses using the number of pain locations as the main independent variable supported the results (table 5). One pain location had a short-term within-individual association with SA in the low occupational class (1.38 $[1.20-1.60])$, while the association was not statistically significant in the high occupational class (1.11 [0.951.29]). Two pain locations showed significant shortterm association with SA for both occupational groups (IRR=1.46 [1.21-1.75] for the low occupational class and IRR=1.30 [1.07-1.58] for the high occupational 
Table 2 The number of changes in the pain status

Pain

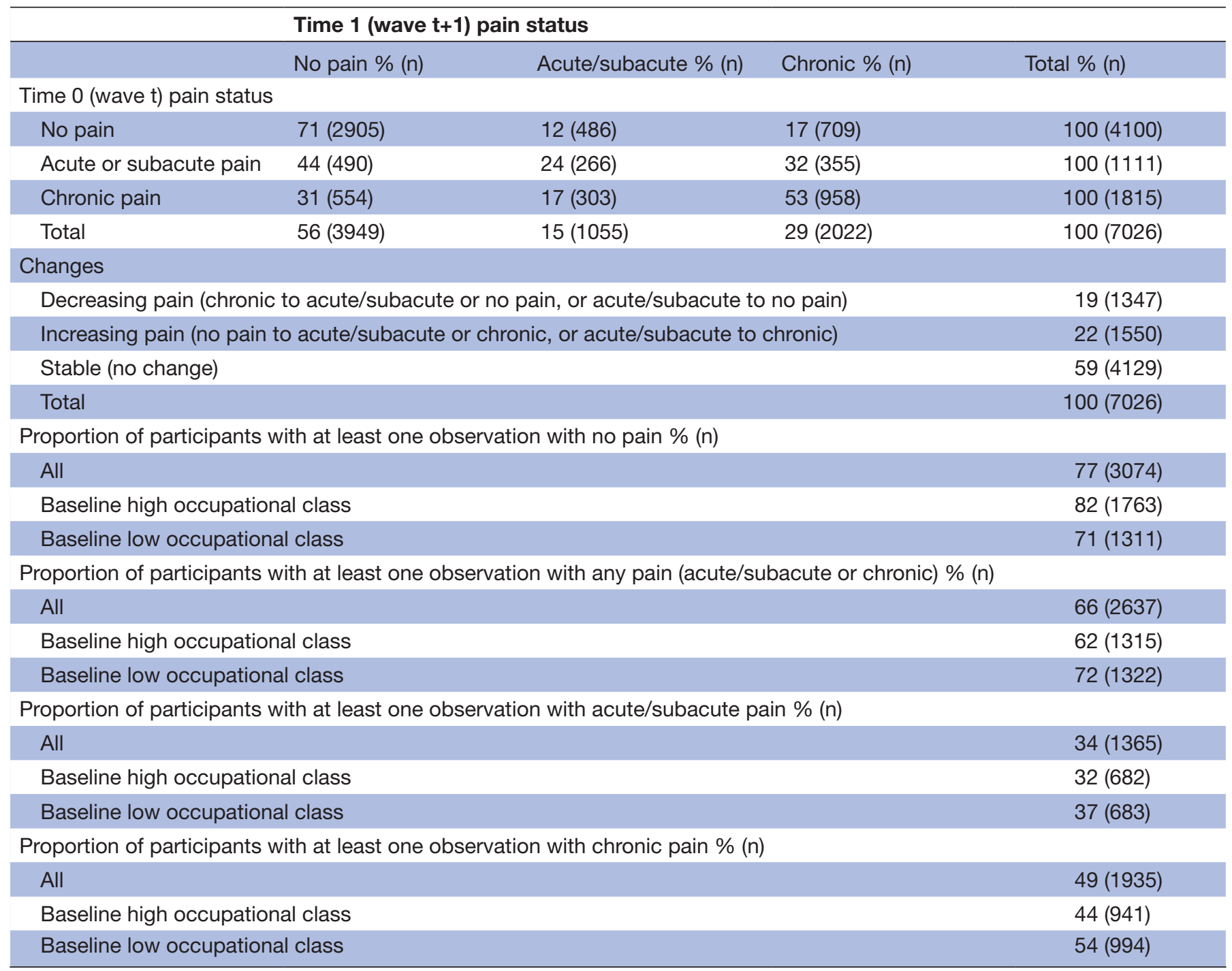

class). Regarding the long-term associations, the number of pain locations showed fairly linear within-individual association with SA without significant occupational class differences.

\section{Between-individual and within-individual estimate comparison}

As shown in figure 1, the comparison of the within-individual and between-individual estimates indicates that controlling for the time-invariant unobservable variables attenuates the between-individual association of pain with SA. For acute/subacute and chronic pain and the two SA indicators, the between-individual estimates were significantly larger than the within-individual estimates which controlled for all time-invariant characteristics (model 1 and model 2). In line with this, the results for multisite pain suggest (model 3 and model 4) that the between-individual estimates may provide overstated effect sizes regarding the pain-SA association.

\section{DISCUSSION}

This study investigated the within-individual association between pain and SA among midlife employees, and examined potential differences between those in low and high occupational classes. The main findings were the following. First, changes in pain were associated with short-term changes in the number of SA days among all employees, and that the effect of acute/subacute and single located pain on SA was greater in employees in the low occupational class than in those in the high occupational class. These findings were mainly similar when focusing on multisite pain as an alternative measure of pain. Second, chronic pain showed a somewhat stronger within-individual association than acute/subacute pain, and the long-term associations between pain and SA were somewhat weaker than the short-term ones. Third, regarding the other predictors used in this study, within-individual changes in long-standing illness, CMDs and working conditions were associated with corresponding short-term changes in SA. 
Table 3 Within-individual short-term associations between acute/subacute and chronic pain, and sickness absence days

\begin{tabular}{|c|c|c|c|c|}
\hline \multirow[b]{2}{*}{ Model } & \multirow{2}{*}{$\begin{array}{l}\text { All } \\
\text { IRR }(95 \% \mathrm{Cl})\end{array}$} & \multirow{2}{*}{$\begin{array}{l}\text { High occupational } \\
\text { class } \\
\text { IRR }(95 \% \mathrm{Cl}) \\
\end{array}$} & \multirow{2}{*}{$\begin{array}{l}\text { Low occupational } \\
\text { class } \\
\text { IRR }(95 \% \mathrm{Cl}) \\
\end{array}$} & \multirow{2}{*}{$\begin{array}{l}P \text { value for the } \\
\text { occupational } \\
\text { class } \\
\text { interactiont }\end{array}$} \\
\hline & & & & \\
\hline \multicolumn{5}{|l|}{ Pain (ref group: no pain) } \\
\hline Acute or subacute pain & $1.13^{\star}(1.01$ to 1.27$)$ & 1.05 (0.89 to 1.24$)$ & $1.29^{\star \star}(1.10$ to 1.50$)$ & 0.051 \\
\hline Chronic pain & $1.32^{\star \star \star}(1.19$ to 1.47$)$ & $1.25^{\star \star}(1.08$ to 1.46$)$ & $1.43^{\star \star \star}(1.23$ to 1.66$)$ & 0.135 \\
\hline \multicolumn{5}{|l|}{ Health } \\
\hline Long-standing illness & $1.32^{\star \star \star}(1.19$ to 1.46$)$ & $1.22^{*}$ (1.04 to 1.42$)$ & $1.38^{\star \star \star}(1.19$ to 1.60$)$ & \\
\hline Common mental disorders & $1.53^{\star \star \star}(1.38$ to 1.69$)$ & $1.56^{\star \star \star}(1.36$ to 1.80$)$ & $1.58^{\star \star \star}(1.37$ to 1.83$)$ & \\
\hline \multicolumn{5}{|l|}{ Working conditions } \\
\hline Mentally strenuous work & 0.99 (0.86 to 1.14$)$ & 0.94 (0.78 to 1.13$)$ & $1.07(0.87$ to 1.31$)$ & \\
\hline Physically strenuous work & $1.33^{\star \star *}(1.18$ to 1.50$)$ & 1.15 (0.95 to 1.40$)$ & $1.35^{\star \star *}(1.15$ to 1.58$)$ & 0.228 \\
\hline Low job control & $1.06(0.94$ to 1.20$)$ & 1.20 (0.97 to 1.49$)$ & 0.98 (0.84 to 1.15$)$ & 0.129 \\
\hline Number of observations & 11009 & 6257 & 4752 & \\
\hline
\end{tabular}

Short-term association is measures by SA days in the survey year. All models are additionally adjusted for survey wave, marital status, night/ shift work and part-time work.

${ }^{*} \mathrm{p}<0.05 ;{ }^{* *} \mathrm{p}<0.01 ;{ }^{* \star *} \mathrm{p}<0.001$.

†Interaction terms for variables differed in the stratified models included to a single model.

IRRs, incidence rate ratios and their $95 \%$ Cls.

The results are in line with the previous studies using between-individual methodological strategies $^{2-5} 71028$ although the risk estimates obtained in the present study are somewhat lower than the ones in the previous studies. For example, an earlier study with the present cohort showed that female employees reporting acute/subacute and chronic pain had a 1.37 and 1.53-fold increased rate of medium-length SA spells (4-14 days of absence) compared with those not reporting any pain. ${ }^{5}$

Nevertheless, the results suggest that the omitted variable bias might be an important factor to be considered in the research on the pain-SA association. Our models showed that the within-individual risk estimates were consistently smaller than the between-individual estimates even after adjusting for a number of time-invariant characteristics.

Table 4 Within-individual long-term associations between acute/subacute and chronic pain, and sickness absence days

\begin{tabular}{|c|c|c|c|c|}
\hline \multirow[b]{2}{*}{ Model } & \multirow{2}{*}{$\begin{array}{l}\text { All } \\
\text { IRR }(95 \% \mathrm{Cl})\end{array}$} & \multirow{2}{*}{$\begin{array}{l}\text { High occupational } \\
\text { class } \\
\text { IRR }(95 \% \mathrm{Cl}) \\
\end{array}$} & \multirow{2}{*}{$\begin{array}{l}\text { Low occupational } \\
\text { class } \\
\text { IRR }(95 \% \mathrm{Cl}) \\
\end{array}$} & \multirow{2}{*}{$\begin{array}{l}\text { P value for the } \\
\text { occupational } \\
\text { class } \\
\text { interactiont }\end{array}$} \\
\hline & & & & \\
\hline \multicolumn{5}{|l|}{ Pain (ref group: no pain) } \\
\hline Acute or subacute pain & $1.12^{*}(1.02$ to 1.24$)$ & 1.10 (0.95 to 1.27$)$ & $1.17^{\star}$ (1.01 to 1.34$)$ & 0.596 \\
\hline Chronic pain & $1.26^{\star \star \star}(1.14$ to 1.39$)$ & $1.22^{\star \star}(1.05$ to 1.41$)$ & $1.31^{\star \star \star}(1.14$ to 1.51$)$ & 0.565 \\
\hline \multicolumn{5}{|l|}{ Health } \\
\hline Long-standing illness & 1.11 (1.00 to 1.22$)$ & $1.21^{*}(1.05$ to 1.41$)$ & 1.01 (0.88 to 1.17$)$ & 0.073 \\
\hline Common mental disorders & $0.98(0.89$ to 1.07$)$ & $1.03(0.89$ to 1.18$)$ & 0.92 (0.81 to 1.04$)$ & \\
\hline \multicolumn{5}{|l|}{ Working conditions } \\
\hline Mentally strenuous work & $1.14^{*}(1.01$ to 1.30$)$ & $1.21^{*}(1.03$ to 1.43$)$ & $1.03(0.84$ to 1.26$)$ & 0.272 \\
\hline Physically strenuous work & $1.17^{\star \star}$ (1.04 to 1.30$)$ & $1.06(0.87$ to 1.28$)$ & $1.21^{*}(1.04$ to 1.39$)$ & 0.261 \\
\hline Low job control & 1.09 (0.97 to 1.22$)$ & 1.07 (0.87 to 1.32$)$ & $1.12(0.98$ to 1.29$)$ & \\
\hline Number of observations & 8339 & 4654 & 3685 & \\
\hline
\end{tabular}

Long-term association is measures by SA days the 2 years after the survey. All models are additionally adjusted for survey wave, marital status, night/shift work and part-time work.

${ }^{*} p<0.05 ;{ }^{* *} p<0.01 ;{ }^{* * *} p<0.001$.

†Interaction terms for variables differed in the stratified models included to a single model.

IRRs, incidence rate ratios and their $95 \%$ Cls. 
Table 5 Within-individual association between multisite pain and sickness absence days

\begin{tabular}{|c|c|c|c|c|}
\hline \multirow[b]{2}{*}{ Pain } & \multirow{2}{*}{$\begin{array}{l}\text { All } \\
\text { IRR }(95 \% \text { Cl) }\end{array}$} & \multirow{2}{*}{$\begin{array}{l}\text { High occupational } \\
\text { class } \\
\text { IRR }(95 \% \mathrm{Cl})\end{array}$} & \multirow{2}{*}{$\begin{array}{l}\text { Low occupational } \\
\text { class } \\
\text { IRR }(95 \% \mathrm{Cl})\end{array}$} & \multirow{2}{*}{$\begin{array}{l}\text { P value for the } \\
\text { occupational } \\
\text { class } \\
\text { interactiont }\end{array}$} \\
\hline & & & & \\
\hline \multicolumn{5}{|l|}{ Short-term association } \\
\hline \multicolumn{5}{|l|}{ Pain (ref group: no pain) } \\
\hline One pain location & $1.22^{\star \star \star}(1.10$ to 1.36$)$ & 1.11 (0.95 to 1.29$)$ & $1.38^{\star \star \star}(1.20$ to 1.60$)$ & 0.012 \\
\hline Two pain locations & $1.35^{\star \star \star}(1.19$ to 1.54$)$ & $1.30^{\star \star}(1.07$ to 1.58$)$ & $1.46^{\star \star \star}(1.21$ to 1.75$)$ & 0.293 \\
\hline Three or more pain locations & $1.21^{\star}(1.04$ to 1.40$)$ & 1.19 (0.95 to 1.50$)$ & $1.26^{\star}(1.03$ to 1.55$)$ & 0.706 \\
\hline Number of observations & 10849 & 6181 & 4668 & \\
\hline \multicolumn{5}{|l|}{ Long-term association } \\
\hline \multicolumn{5}{|l|}{ Pain (ref group: no pain) } \\
\hline One pain location & $1.16^{* *}(1.05$ to 1.27$)$ & 1.15 (1.00 to 1.33$)$ & $1.19^{*}(1.04$ to 1.37$)$ & 0.529 \\
\hline Two pain locations & $1.23^{\star \star \star}(1.09$ to 1.39$)$ & 1.16 (0.97 to 1.40$)$ & $1.27^{\star \star}(1.08$ to 1.51$)$ & 0.528 \\
\hline Three or more pain locations & $1.36^{\star \star *}(1.19$ to 1.55$)$ & 1.17 (0.94 to 1.45$)$ & $1.55^{\star \star \star}$ (1.30 to 1.86$)$ & 0.042 \\
\hline Number of observations & 8214 & 4600 & 3614 & \\
\hline
\end{tabular}

All models adjusted for common mental disorders, long-standing illness, physical and mental work environments, job control, survey wave, marital status, night/shift work and part-time work.

${ }^{*} p<0.05 ;{ }^{* *} p<0.01 ;{ }^{* \star *} p<0.001$.

†Interaction terms for variables differed in the stratified models included to a single model.

Short-term, within the survey year; long-term, during 2 years after the survey year.

IRRs, incidence rate ratios and their $95 \%$ Cls.

This finding indicates that those employees who report pain at some point in the study are also predisposed to higher levels of SA on the occasions when they do not report pain. Our within-individual analytic strategy takes this into account by using each employee as his/her own control. This confirms that the risk of SA is further elevated on the occasions that individuals did report pain. Our analysis approach, therefore, has a significant advantage compared with many previous studies that are prone to the omitted variable bias. ${ }^{2-5} 71028$

Pain had a stronger short-term association with SA among the employees in the low occupational class than among those in high occupational class when all time-invariant characteristics were considered. This finding is consistent with previous evidence indicating that working environment is a moderator of musculoskeletal disorders or pain related SA. ${ }^{94041}$ Haukka $e t$ a ${ }^{\theta}$ found that having a high occupational class was a protective factor for SA in a nationally representative sample comprising Finnish employees with cross-sectionally measured multisite pain. However, somewhat contrary evidence is provided by Andersen $e t a l,{ }^{4}$ who found that neck/shoulder pain is a specific risk factor for long SA episode for white-collar workers but not for blue-collar workers.

A number of factors might explain the finding that occupational class is a moderator in the association between pain and SA. Pain could be triggered by different work exposures, and it could specifically impair the capacity related to the varying types of occupational physical activities in the low occupational class. Thus, similar pain might have a different effect on work ability among people with distinct work exposures. ${ }^{11}$ This is in line with the well-known conceptualisation of work disability as a mismatch between health and work environment. ${ }^{42}$

Alternatively, the pain reported by the employees in the low occupational class might be qualitatively different from that in the high occupational class and therefore having a stronger effect on work disability. ${ }^{1}$ However, our descriptive analysis showed that among those reporting pain in a single location, the pain locations reported were similar between the high and low occupational groups (data not shown). Nevertheless, we were not able to determine whether the pain intensity differed between the groups, which may explain the indication for an interaction effect.

Finally, modification of working arrangements may be more likely to be implemented or more feasible within the high occupational class, allowing these employees to better cope with pain. For example, it is shown that the ability to adjust working time might prevent SA among employees with multisite pain, ${ }^{9}$ and working time adjustments are generally more common in the high occupational class. More evidence is needed to investigate thoroughly the work-related factors potentially moderating the pain-SA association. Identifying groups for which pain prevention would be particularly beneficial could help modify workplace practices, target appropriate interventions and thereby ease the overall economic burden of SA.

Concerning the other predictors used in this study, CMDs, long-standing illness and physically and mentally strenuous work all had a within-individual association 
with SA. We found that CMDs were associated with a 1.5-fold increase in the rate of SA in the short-term, while the association was non-significant in the longer term. An Australian study found a small within-individual association between severe depression and SA, and similarly with the present study, showed that, due to the omitted variable bias, between-individual comparison might provide an overstated effect of mental ill-health on SA. ${ }^{19}$ Furthermore, our results showed that changes in the reported physically strenuous work had a shortterm and longer-term within-individual association with SA. This finding is also supported by a body of previous observational studies. ${ }^{41}{ }^{43}$ Overall, our findings on the between-individual and within-individual estimate comparisons are in line with the studies showing that the association between SA and various predictors somewhat attenuates when unobserved characteristics are controlled for. ${ }^{18} 19$

\section{Methodological considerations}

This study used a longitudinal occupational cohort with high overall response rates, long follow-up and register-based data on SA. ${ }^{24}$ Moreover, we used a within-individual analytical strategy in which the potential bias due to omitted unobservable time-invariant variables is averted ${ }^{14}$ although the method is still not sufficient for causal interpretation as such. Moreover, we were able to study both short-term and longer-term associations between pain and SA. Finally, an important advantage was that our sample comprised employees of the same employer having similar policies for SA and healthcare coverage.

However, some limitations are important to consider when interpreting the findings. First, a selection bias might influence the results. The within-individual estimation can handle sample selection if the selection is due to time-invariant characteristics of the employees. ${ }^{14}$ However, the selection related to time-variant characteristics, such as deteriorating health, can have an influence on the results. Importantly, the healthy worker effect might exist as those with the most disabling pain are more likely to retire early due to disability and drop out from the study population. Due to such potential selection biases, it can be argued that the results and estimates, especially from the long-term association, are likely to be conservative especially for the low occupational group who are more likely to retire early. This might explain the finding that long-standing illness showed a somewhat stronger long-term association with SA in the high occupational group. Furthermore, around $22 \%$ of the original study population did not provide consent for record linkage. Although those who did not give consent did not differ in terms of pain measures, they were more likely to report adverse working conditions, which might cause some bias regarding these measures.

Second, pain was self-reported and assessed only in surveys conducted over a long time-frame. We did not have information on pain reported in a healthcare setting nor the date on which the pain started. Nonetheless, pain is a subjective condition, ${ }^{44}$ and most other epidemiological studies rely on such self-reported data. Third, as we had a female dominated cohort of public sector employees only, this could affect generalisability of our findings. For example, women typically report more pain symptoms than men. ${ }^{45}$ Fourth, although the models controlled for all time-invariant (ie, including unobserved characteristics) and several important timevarying characteristics, other time-varying factors that may cause both SA and pain were not measured or able to be controlled, for example, changes in personal relationships. Fifth, we did not have access to information on the diagnostic causes for SA, as this information is available only for longer SA periods. It might be possible that the reasons for SA differ substantially between occupations. Sixth, we lacked the information on SA for the employees who became unemployed or changed their employer. However, both of these categories were very small.

It is important to note that the within-individual method calculates the coefficients as a combined effect of both positive and negative changes in the exposures. Our explorative analysis with alternative approach showed that both increases in pain (compared with stable no pain) and decreases in pain (compared with stable pain) were associated with SA but the estimates of increases in pain were somewhat larger than the estimates of pain decreases (see supplementary materials online supplementary table S5). Given this and the fact that pain increased overall within the study period, our risk estimates were more likely to reflect the effect of increases in pain. Furthermore, in within-individual analyses, the estimates can be imprecise for variables with little within-individual changes over time. This might cause some concerns regarding our estimates, including pain in multiple locations, containing less within-individual variation.

Some clinical conditions might obviously explain both reported pain and SA. We adjusted our models for longstanding illness, but it is possible that some residual bias remains. We did not adjust for clinically assessed musculoskeletal disorders or self-rated health as these are not separate conditions from reported pain. However, our sensitivity analyses additionally adjusting for severe pain-related illnesses (binary indicator of reported doctor diagnosed rheumatoid arthritis, cancer, arthrosis or migraine) had only a minor effect on the estimates and did not change the findings (data not shown).

\section{CONCLUSION}

Pain increases the short-term and long-term risks of SA. When all time-invariant characteristics are considered, pain might more likely to lead to SA in those with low occupational class than in those with high occupational class. Improvements in physical working environment, pain prevention and adjustment to accommodate pain are likely to decrease SA days. 


\section{Author affiliations}

${ }^{1}$ Finnish Institute of Occupational Health, Helsinki, Finland

${ }^{2}$ Centre for Mental Health, Melbourne School of Population and Global Health, The University of Melbourne, Victoria, Australia

${ }^{3}$ Melbourne Institute of Applied Economic and Social Research, The University of Melbourne, Victoria, Australia

${ }^{4}$ Department of Public Health, University of Helsinki, Helsinki, Finland

${ }^{5}$ Development and Innovation, Laurea University of Applied Sciences, Unit of

Research, Vantaa, Finland

${ }^{6}$ Faculty of Social Sciences, University of Helsinki, Helsinki, Finland ${ }^{7}$ SWPS University of Social Sciences and Humanities, Wroclaw, Poland ${ }^{8}$ Administrative Data Research Centre-Northern Ireland (ADRC-NI), Queen's University Belfast, Belfast, UK

Contributors AH and TL had the original idea for the present paper. AH conducted all phases of the statistical analyses and wrote the first draft of the manuscript and the later versions. RS, PB, AK, MM, AR, OP, EL, OR and TL interpreted the results, reviewed and revised the manuscript. All the authors approved the final manuscript for submission to this journal.

Funding TL and AH are supported by the Academy of Finland (Grants \#287488 and \#319200). AK is supported by the Economic and Social Research Council (ESRC) (grant ES/L007509/1). OR is supported by the Academy of Finland (grant 1294514) and the Juho Vainio Foundation. OP is supported by the Academy of Finland (grant 1294514). MM is supported by the Finnish Work Environment Fund (grant 115182) and the Juho Vainio Foundation. PB is supported by a Future Fellowship from the Australian Research Council (FT13101444)

Competing interests None declared.

Patient consent for publication Not required.

Ethics approval The Ethics Committees of the Department of Public Health, University of Helsinki and the health authorities of the City of Helsinki.

Provenance and peer review Not commissioned; externally peer reviewed.

Data sharing statement № additional data are available.

Open access This is an open access article distributed in accordance with the Creative Commons Attribution Non Commercial (CC BY-NC 4.0) license, which permits others to distribute, remix, adapt, build upon this work non-commercially, and license their derivative works on different terms, provided the original work is properly cited, appropriate credit is given, any changes made indicated, and the use is non-commercial. See: http://creativecommons.org/licenses/by-nc/4.0/.

\section{REFERENCES}

1. Saastamoinen $P$, Leino-Arjas $P$, Laaksonen $M$, et al. Socio-economic differences in the prevalence of acute, chronic and disabling chronic pain among ageing employees. Pain 2005;114:364-71.

2. Haukka E, Kaila-Kangas L, Luukkonen R, et al. Predictors of sickness absence related to musculoskeletal pain: a two-year follow-up study of workers in municipal kitchens. Scand $J$ Work Environ Health 2014:40:278-86.

3. Kääriä S, Laaksonen M, Leino-Arjas $P$, et al. Low back pain and neck pain as predictors of sickness absence among municipal employees. Scand J Public Health 2012;40:150-6.

4. Andersen LL, Mortensen OS, Hansen JV, et al. A prospective cohort study on severe pain as a risk factor for long-term sickness absence in blue- and white-collar workers. Occup Environ Med 2011;68:590-2.

5. Saastamoinen P, Laaksonen M, Lahelma $\mathrm{E}$, et al. The effect of pain on sickness absence among middle-aged municipal employees. Occup Environ Med 2009;66:131-6.

6. de Fernandes RC, Burdorf A. Associations of multisite pain with healthcare utilization, sickness absence and restrictions at work. Int Arch Occup Environ Health 2016;89:1039-46.

7. Saastamoinen $P$, Leino-Arjas $P$, Rahkonen $O$, et al. Separate and combined associations of pain and emotional exhaustion with sickness absence. Pain 2016;157:186-93.

8. Eckhoff C, Straume B, Kvernmo S. Multisite musculoskeletal pain in adolescence as a predictor of medical and social welfare benefits in young adulthood: The Norwegian Arctic Adolescent Health Cohort Study. Eur J Pain 2017;21:1697-706.

9. Haukka E, Ojajärvi A, Kaila-Kangas L, et al. Protective determinants of sickness absence among employees with multisite pain-a 7-year follow-up. Pain 2017;158:220-9.
10. Burdorf A, Jansen JP. Predicting the long term course of low back pain and its consequences for sickness absence and associated work disability. Occup Environ Med 2006;63:522-9.

11. Neupane S, Pensola T, Haukka E, et al. Does physical or psychosocial workload modify the effect of musculoskeletal pain on sickness absence? A prospective study among the Finnish population. Int Arch Occup Environ Health 2016;89:719-28.

12. Wooldridge JM. Introductory econometrics: A modern approach: Nelson Education. 2015.

13. Gardiner JC, Luo Z, Roman LA. Fixed effects, random effects and GEE: what are the differences? Stat Med 2009;28:221-39.

14. Allison PD. Fixed effects regression models: SAGE publications. USA: University of Pennsylvania, 2009.

15. Marchand F, Perretti M, McMahon SB. Role of the immune system in chronic pain. Nat Rev Neurosci 2005;6:521-32.

16. Ingelsrud $\mathrm{MH}$. Reorganization increases long-term sickness absence at all levels of hospital staff: panel data analysis of employees of Norwegian public hospitals. BMC Health Serv Res 2014;14:411.

17. Østhus S, Mastekaasa A. The impact of downsizing on remaining workers' sickness absence. Soc Sci Med 2010;71:1455-62.

18. Milner A, Butterworth P, Bentley R, et al. Sickness absence and psychosocial job quality: an analysis from a longitudinal survey of working Australians, 2005-2012. Am J Epidemiol 2015;181:781-8.

19. Wooden M, Bubonya M, Cobb-Clark D. Sickness absence and mental health: evidence from a nationally representative longitudinal survey. Scand J Work Environ Health 2016;42:201-8.

20. Holtermann A, Hansen JV, Burr H, et al. Prognostic factors for longterm sickness absence among employees with neck-shoulder and low-back pain. Scand J Work Environ Health 2010;36:34-41.

21. Airila A, Hakanen JJ, Luukkonen R, et al. Developmental trajectories of multisite musculoskeletal pain and depressive symptoms: the effects of job demands and resources and individual factors. Psychol Health 2014;29:1421-41.

22. Saastamoinen $P$, Leino-Arjas $P$, Laaksonen $M$, et al. Pain and health related functioning among employees. J Epidemiol Community Health 2006;60:793-8.

23. Haukka E, Kaila-Kangas L, Ojajärvi A, et al. Multisite musculoskeletal pain predicts medically certified disability retirement among Finns. European Journal of Pain 2015;19:1119-28.

24. Lahelma E, Aittomäki A, Laaksonen M, et al. Cohort profile: the Helsinki Health Study. Int J Epidemiol 2013;42:722-30.

25. Virtanen M, Lallukka T, Ervasti J, et al. The joint contribution of cardiovascular disease and socioeconomic status to disability retirement: A register linkage study. Int J Cardiol 2017;230:222-7.

26. Merskey HE. Classification of chronic pain: descriptions of chronic pain syndromes and definitions of pain terms. Pain 1986;3:S1-S226.

27. Saastamoinen $P$, Laaksonen $M$, Kääriä SM, et al. Pain and disability retirement: a prospective cohort study. Pain 2012;153:526-31.

28. Haukka E, Kaila-Kangas L, Ojajärvi A, et al. Pain in multiple sites and sickness absence trajectories: a prospective study among Finns. Pain 2013;154:306-12.

29. Haukka E, Kaila-Kangas L, Ojajärvi A, et al. Multisite musculoskeletal pain predicts medically certified disability retirement among Finns. Eur J Pain 2015;19:1119-28.

30. Pevalin DJ. Multiple applications of the GHQ-12 in a general population sample: an investigation of long-term retest effects. Soc Psychiatry Psychiatr Epidemiol 2000;35:508-12.

31. Lahelma E, Pietiläinen $\mathrm{O}$, Rahkonen $\mathrm{O}$, et al. Common mental disorders and cause-specific disability retirement. Occup Environ Med 2015;72:181-7.

32. Hoogendoorn WE, Bongers PM, de Vet HC, et al. High physical work load and low job satisfaction increase the risk of sickness absence due to low back pain: results of a prospective cohort study. Occup Environ Med 2002;59:323-8.

33. Laaksonen M, Pitkäniemi J, Rahkonen O, et al. Work arrangements, physical working conditions, and psychosocial working conditions as risk factors for sickness absence: Bayesian analysis of prospective data. Ann Epidemiol 2010;20:332-8.

34. Eriksen W, Bruusgaard D, Knardahl S. Work factors as predictors of intense or disabling low back pain; a prospective study of nurses aides. Occup Environ Med 2004;61:398-404.

35. Kivimäki M, Sutinen R, Elovainio M, et al. Sickness absence in hospital physicians: 2 year follow up study on determinants. Occup Environ Med 2001;58:361-6.

36. Allison PD, Waterman RP. 7. Fixed-Effects Negative Binomial Regression Models. Sociol Methodol 2002;32:247-65.

37. Allison PD. Fixed effects regression methods for longitudinal data using SAS: Sas Institute. 2005.

38. Dieleman JL, Templin T. Random-effects, fixed-effects and the within-between specification for clustered data in observational health studies: a simulation study. PLoS One 2014;9:e110257. 
39. Schunck R, Perales F. Within- and Between-cluster Effects in Generalized Linear Mixed Models: A Discussion of Approaches and the Xthybrid command. Stata J 2017;17:89-115.

40. de Vries HJ, Reneman MF, Groothoff JW, et al. Workers who stay at work despite chronic nonspecific musculoskeletal pain: do they differ from workers with sick leave? J Occup Rehabil 2012;22:489-502.

41. Leijten FR, van den Heuvel SG, Ybema JF, et al. Do work factors modify the association between chronic health problems and sickness absence among older employees? Scand J Work Environ Health 2013;39:477-85.
42. IImarinen J. Work ability--a comprehensive concept for occupational health research and prevention. Scand J Work Environ Health 2009;35:1-5.

43. Lund T, Labriola M, Christensen KB, et al. Physical work environment risk factors for long term sickness absence: prospective findings among a cohort of 5357 employees in Denmark. BMJ 2006;332:449-52.

44. Croft P, Blyth FM, van der Windt D. Chronic pain epidemiology: from aetiology to public health: Oxford University Press, 2010.

45. Schneider S, Randoll D, Buchner M. Why do women have back pain more than men? A representative prevalence study in the federal republic of Germany. Clin J Pain 2006;22:738-47. 